\title{
MENINGKATKAN PEMANFAATAN PASAR DIGITAL UNTUK EKSPOR PRODUK UMKM DI JAWA TIMUR
}

\author{
Megahnanda Alidyan Kresnawati ${ }^{1}$, Resa Rasyidah'1) \\ 1)Program Studi Hubungan Internasional, Fakultas IImu Politik dan IImu Sosial, UPN “Veteran” Jawa Timur, Indonesia \\ Corresponding author : Resa Rasyidah \\ E-mail : resa.rasyidah@gmail.com
}

Diterima 22 Oktober 2021, Direvisi 03 November 2021, Disetujui 03 November 2021

\begin{abstract}
ABSTRAK
Sektor usaha mikro, kecil dan menengah (UMKM) memiliki peran yang sangat penting dalam membangkitkan perekonomian di daerah, tidak terkecuali Jawa Timur. Kontribusi UMKM dalam peningkatan perekonomian provinsi Jawa Timur merupakan yang terbesar dibandingkan sektor lainnya. Gubernur Jawa Timur Khofifah Indar Parawansa pada acara Briliant Preneur 2021 bahwa kontribusi UMKM terhadap produk domestik regional bruto (PDRB) di Jawa Timur bahkan mencapai 57,25 persen. Agar pasar UMKM dapat lebih luas hingga ke luar negeri, maka pelatihan ekspor kepada para pelaku UMKM di Jawa Timur perlu diadakan. Kegiatan "Workshop Peluang Ekspor UMKM Melalui Pasar Digital" dilakukan untuk memfasilitasi para pelaku UMKM dalam memulai ekspor produk mereka. Kegiatan yang ini diikuti kurang lebih 50 perwakilan UMKM di Jawa Timur ini terdiri dari 3 tahap kegiatan, tahap persiapan, tahap pelaksanaan, dan tahap monitoring evaluasi. Pada tahap persiapan, panitia melakukan koordinasi internal juga memberikan lembar untuk diisi dengan data usaha pelaku UMKM. Pada tahap pelaksanaan, workshop dilakukan melalui dua (2) sesi. Sesi pertama merupakan pemberian materi terkait pemanfaatan pasar digital untuk ekspor produk-produk UMKM Jawa Timur. Pada sesi kedua, para peserta dapat langsung melakukan praktek atas materi yang diberikan, dan dapat melaporkan hasilnya. Monitoring dan evaluasi pelaksanaan dilakukan dengan mengisi lembar evaluasi kegiatan, baik yang dilakukan oleh narasumber terhadap pelaksanaan acara maupun para pelaku UMKM terhadap pelaksanaan acara. Seluruh peserta workshop dapat mengikuti dengan baik walaupun ada beberapa kendala saat sesi praktek seperti banyaknya penggunaan bahasa asing dalam praktek pembuatan akun website e-commerce maupun pembuatan deskripsi produk.
\end{abstract}

Kata kunci: ekspor; pasar digital; UMKM.

\begin{abstract}
The micro, small and medium enterprise (MSMEs) sector has a very important role in generating the economy in the region. East Java is no exception. The contribution of MSMEs in improving the economy of East Java province is the largest compared to other sectors. East Java Governor Khofifah Indar Parawansa at the Briliant Preneur 2021 event that the contribution of MSMEs to gross regional domestic product (GRDP) in East Java even reached 57.25 percent. So that the MSME market can be wider overseas, then export training for MSME actors in East Java needs to be held. The activity "Workshop on MSME Export Opportunities Through Digital Markets" was carried out to facilitate MSMEs players in exporting their products. This activity, attended by approximately 50 representatives of MSMEs in East Java, consisted of 3 stages of activity, the preparation stage, the implementation stage, and the evaluation monitoring stage. The committee carried out internal coordination at the preparation stage and provided a sheet filled with business data for MSME actors. The workshop was conducted in two (2) sessions at the implementation stage. The first session was the provision of material related to the use of the digital market to export East Java MSME products. In the second session, the participants could immediately practice the provided material and report the results. Monitoring and evaluation of implementation are carried out by filling out activity evaluation sheets, both those carried out by resource persons on the implementation of the event and MSME actors on the implementation of the event. All workshop participants were able to follow well. However, there were several obstacles during the practice session, such as using foreign languages to create e-commerce website accounts and making product descriptions.
\end{abstract}

Keywords: exports; digital market; MSMEs. 


\section{PENDAHULUAN}

Awal tahun 2020 merupakan awal terjadinya banyak perubahan bagi kehidupan ekonomi masyarakat di Indonesia akibat pandemi Covid-19. Perubahan ini terjadi karena adanya kebijakan pembatasan sosial berskala besar yang diterapkan oleh pemerintah di hampir semua daerah di Indonesia, demi mengurangi resiko penularan Covid-19. Pembatasan ini memaksa masyarakat untuk lebih banyak mengerjakan pekerjaannya dari rumah masing-masing dengan memanfaatkan teknologi yang ada. Kegiatan ini dilakukan secara massal sehingga berdampak besar pada perekonomian Indonesia. Negara ini mengalami penurunan dalam perekonomian selama pandemi berlangsung.

Penurunan perekonomian ini dapat dilihat salah satunya dari turunnya angka ekspor Indonesia. Berdasarkan data Badan Pusat Statistik (BPS), Nilai Ekspor Indonesia turun 8,36 persen pada Agustus 2020, dibandingkan setahun sebelumnya, Agustus 2019. Nilai Ekspor Indonesia pada Agustus 2020 mencapai US\$12,46 miliar. Nilai ekspor non migas juga ikut mengalami penurunan sebesar 7,16 persen pada saat yang sama. Pada April 2021, nilai ekspor Indonesia mulai naik signifikan sebesar 51,94 persen mencapai US\$18,48. Sedangkan ekspor non migas mengalami kenaikan 51,08 persen, dengan total volume mencapai US\$17,52. (Pamungkas, 2021)

Meskipun nilai ekspor telah naik, pelaku ekspor masih didominasi oleh pengusaha-pengusaha besar. Sebaliknya, UMKM banyak yang terdampak negatif akibat pandemi Covid-19 yang terjadi sepanjang tahun 2020. Menurut hasil survey Katadata, pendemi Covid-19 menyebabkan dampak negatif terhadap 82,9 persen UMKM. Sebagian lainnya, yakni sebanyak 11.2 persen tidak terdampak dan hanya sebagian kecil yang justru mengalami dampak positif yakni sebanyak 5,9 persen. (Katadata.co.id, 2020)

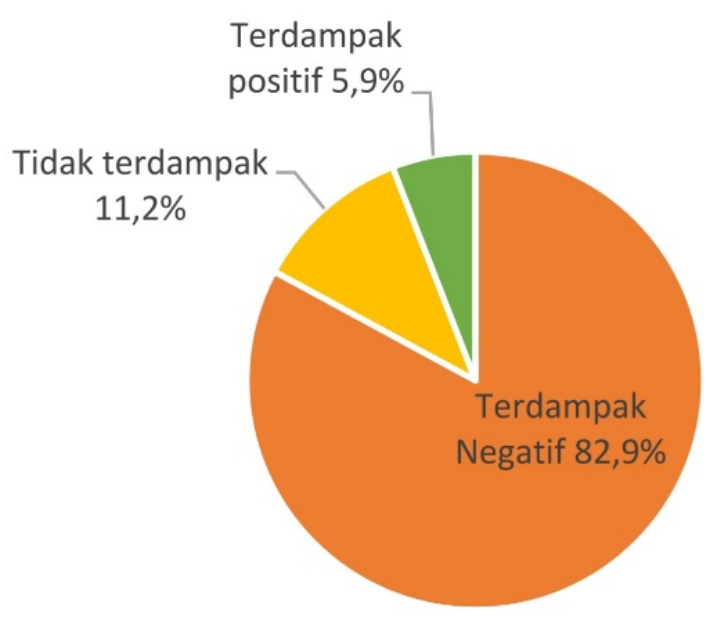

Gambar 1. Dampak Pandemi Covid-19 Terhadap UMKM (Katadata.co.id, 2020)

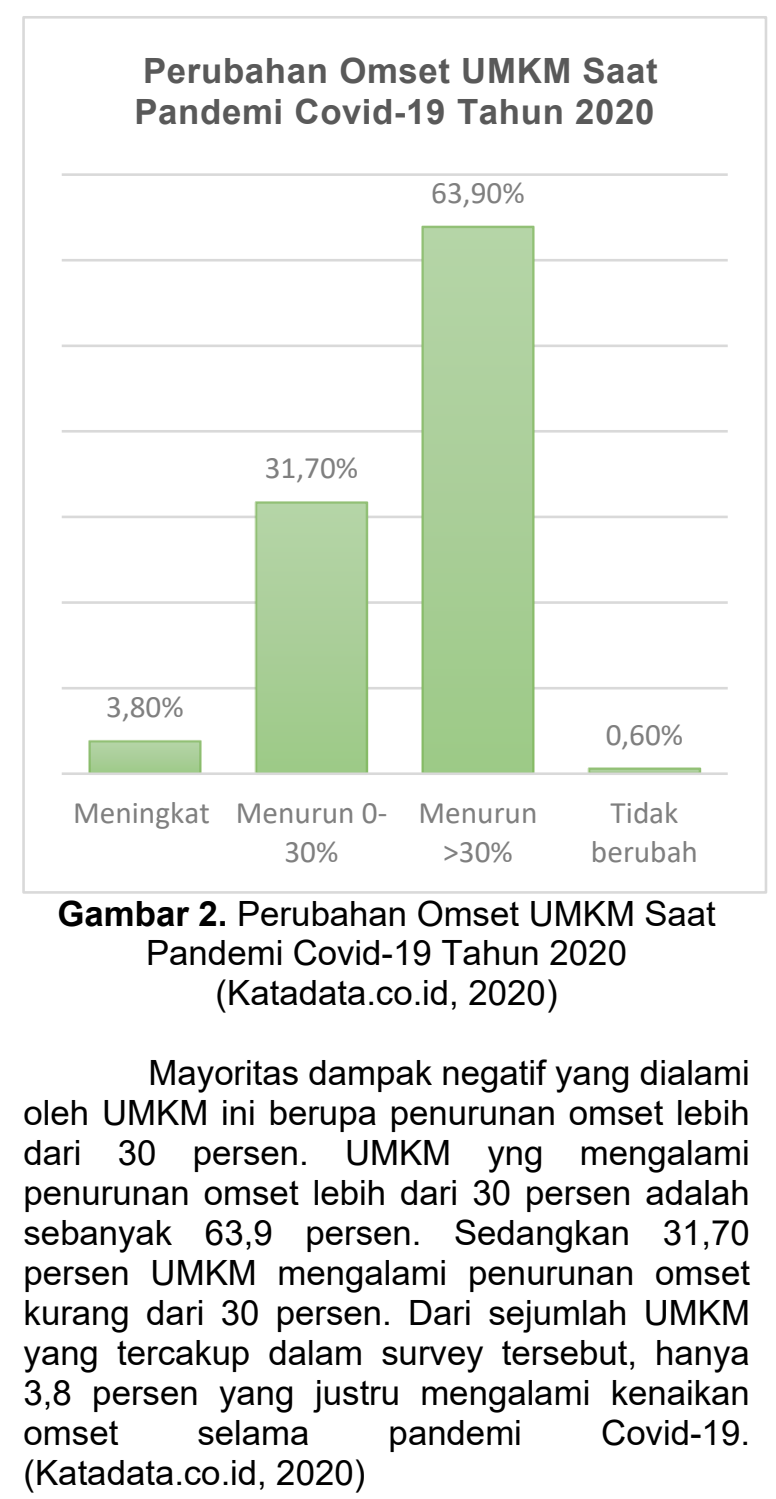


Kondisi UMKM yang demikian ini memerlukan upaya agar dapat bangkit kembali. Salah satu upaya yang dilakukan adalah digitalisasi UMKM, artinya mengupayakannya pemanfaatan pasar digital untuk pemasaran produk-produk UMKM ini hingga ke luar negeri atau ekspor. Digitalisasi UMKM ini dianggap sebagai salah satu strategi UMKM untuk dapat bertahan di tengah pandemi. Pemerintah, khususnya Pemerintah Jawa Timur, juga mendorong agar UMKM masuk ke dalam ekosistem digital. Gubernur Jawa Timur Khofifah Indar Parawansa menyatakan bahwa pemasaran produk-produk UMKM perlu memanfaatkan teknologi agar dapat merambah ke pasar yang lebih luas. (Widarti, 2021)

Pemerintah Jawa Timur sendiri sudah melakukan upaya digitalisasi UMKM diantaranya dengan bekerjasama dengan pihak swasta, salah satunya Grab. Pada Agustus 2020, Grab dengan Program \#TerusUsaha, bekerjasama dengan Pemerintah Jawa Timur memberikan berbagai pelatihan untuk meningkatkan ketrampilan para pelaku UMKM di Jawa Timur, khususnya untuk fokus "go digital". (Kompas.com, 2020)

Pada Maret 2021, Pemerintah Jawa Timur meresmikan Kantor UPT Pelatihan Dinas Koperasi dan UKM Provinsi Jawa Timur, di Malang. UPT ini dapat membantu memajukan para pelaku Koperasi dan UKM di Jawa Timur. Khususnya dalam pengembangan digitalisasi dan teknologi informasi. (Zahro, 2021) Sebanyak 56,9 persen PDRB Provinsi Jawa Timur memang dihasilkan dari sektor UMKM sehingga memang perlu ada upaya lebih untuk mendorong kemajuan UMKM Jawa Timur, khususnya di tengah pandemi Covid-19. Oleh karena itu sebagai bagian dari tridharma perguruan tinggi, kami mengadakan kegiatan pengabdian masyarakat yang bertujuan untuk meningkatkan pemanfaatan pasar digital untuk ekspor produk UMKM Jawa Timur. Sasaran kegiatan ini adalah para pelaku UMKM di Jawa Timur.

\section{METODE}

Kegiatan pengabdian masyarakat ini dilakukan dengan memberikan pelatihan kepada para pelaku UMKM di Jawa Timur. Kegiatan ini terdiri dari 3 tahap kegiatan, tahap persiapan, pelaksanaan, monitoring dan evaluasi.

Pada tahap persiapan panitia selain melakukan koordinasi internal juga memberikan lembar untuk diisi dengan data usaha pelaku UMKM. Melalui data tersebut dapat diketahui seberapa jauh UMKM tersebut mengetahui cara dalam memasarkan produknya, riwayat dalam melakukan ekspor produk maupun harapan dalam mengikuti workshop UMKM tersebut.

Setelah tahap persiapan selesai dilakukan. Pada tahap pelaksanaan, pelatihan tersebut dilakukan melalui dua (2) sesi. Sesi pertama merupakan pemberian materi terkait pemanfaatan pasar digital untuk ekpor produkproduk UMKM Jawa Timur. Sedangkan pada sesi kedua, para peserta pelatihan tersebut dapat langsung melakukan praktek atas materi yang diberikan, dan dapat melaporkan hasilnya. Monitoring dan evaluasi pelaksanaan acara dilakukan dengan mengisi lembar evaluasi acara baik dilakukan oleh narasumber terhadap pelaksanaan acara maupun para pelaku UMKM kepada pelaksanaan Workshop. Metode kegiatan dan partisipasi peserta dapat dilihat melalui Tabel 1 berikut ini:

Tabel 1. Metode Kegiatan dan Partisipasi Peserta

\begin{tabular}{|c|c|c|}
\hline Tujuan Program & Metode & Partisipasi Peserta \\
\hline $\begin{array}{l}\text { Mengidentifikasi } \\
\text { kendala umum } \\
\text { UMKM dalam } \\
\text { memulai ekspor }\end{array}$ & $\begin{array}{l}\text { Penyampaian } \\
\text { materi dan } \\
\text { diskusi }\end{array}$ & $\begin{array}{l}\text { Peserta terlibat aktif } \\
\text { dalam memberikan } \\
\text { gambaran terkait } \\
\text { kendala yang mereka } \\
\text { alami saat memulai } \\
\text { ekspor. } \\
\text { Peserta } \\
\text { mendapatkan } \\
\text { pengetahuan terkait } \\
\text { pemasaran ekspor } \\
\text { dan tata cara } \\
\text { memulai ekspor }\end{array}$ \\
\hline $\begin{array}{l}\text { Memberikan } \\
\text { pemahaman } \\
\text { terkait syarat } \\
\text { menjadi eksportir, } \\
\text { dokumen } \\
\text { pendukung dan } \\
\text { klasifikasi produk } \\
\text { ekspor }\end{array}$ & $\begin{array}{l}\text { Penyampaian } \\
\text { materi dan } \\
\text { diskusi }\end{array}$ & $\begin{array}{l}\text { Peserta terlibat aktif } \\
\text { dalam menyiapkan } \\
\text { dokumen syarat } \\
\text { eksportirnya dan } \\
\text { melakukan klasifikasi } \\
\text { produk ekspornya } \\
\text { masing-masing }\end{array}$ \\
\hline $\begin{array}{l}\text { Pelatihan } \\
\text { langkah-langkah } \\
\text { memulai ekspor }\end{array}$ & $\begin{array}{l}\text { Demo } \\
\text { pendaftaran ke } \\
\text { salah satu } \\
\text { global trade } \\
\text { marketplace } \\
\text { dan membuat } \\
\text { deskripsi } \\
\text { produk }\end{array}$ & $\begin{array}{l}\text { Peserta terlibat aktif } \\
\text { mengikuti demo yang } \\
\text { diberikan sesuai } \\
\text { dengan produk } \\
\text { UMKM yang dimiliki } \\
\text { masing-masing. }\end{array}$ \\
\hline
\end{tabular}

\section{HASIL DAN PEMBAHASAN}

Kegiatan pengabdian masyarakat ini dilakukan pada 29 Agustus 2021. Pelatihan ekspor UMKM ini dilakukan secara daring melalui aplikasi video conference, Zoom Meeting. Peserta kegiatan ini sebanyak kurang lebih 50 orang yang merupakan para pelaku UMKM dari berbagai penjuru di Jawa Timur. Topik Workshop yang dipaparkan adalah "Peluang Ekspor UMKM Melalui Pasar Digital". Materi diawali dengan pembahasan dasardasar untuk memulai ekspor. Secara umum kendala yang dimiliki UMKM untuk memulai 
ekspor adalah bahasa, pengetahuan terkait pemasaran komoditas ekspor, keterbatasan pengetahuan terkait Tata Niaga dan dokumen pendukung ekspor dan pengetahuan tentang akses pembiayaan.

Sejumlah peserta kemudian diminta untuk memberikan gambaran terkait kendala yang mereka alami saat mulai melakukan kegiatan ekspor. Berdasarkan gambaran yang diberikan oleh peserta tersebut, narasumber mengidentifikasi kendala-kendala lain yang mungkin juga mereka hadapi.

Kemudian, peserta worksop diberikan bekal pengetahuan terkait dokumen atau persyaratan untuk menjadi eksportir seperti memiliki Nomor Pokok Wajib Pajak (NPWP) dan dokumen-dokumen lainnya seperti Tanda Dagang Perusahaan (TDP), Surat ljin Usaha Perdagangan (SIUP) atau ljin Usaha Industri (IUI). Pengetahuan tentang langkah awal memulai Ekspor menjadi bahasan berikutnya. Diskusi yang dilakukan terkait hal ini seputar 1) Memiliki atau memilih produk yang tepa, 2) Memahami aturan dan istilah terkait komoditas ekspor, 3) Menyiapkan biaya, 4) Membuat email,web dan katalog produk, 5) Mendaftar ke situs bisnis internasional, 6) Mengikuti pameran produk, 7) Memanfaatkan fasilitas ekspor yang disediakan pemerintah.

Pengetahuan dasar terakhir untuk pelaku UMKM dalam memulai ekspor adalah mengetahui tentang klasifikasi barang ekspor. Klasifikasi ini terbagi dalam tiga (3) kelompok. Kelompok pertama adalah komoditas yang dibatasi ekspornya baik dibatasi dalam jenis atau jumlahnya. Kelompok kedua merupakan barang-barang yang dilarang ekspornya yang tidak boleh diekspor dalam bentuk apapun maupun komoditas bebas ekspor yang komoditasnya tidak masuk kategori dilarang dan dibatasi (Totoaminoto, 2019)

Pada sesi workshop berikutnya dilakukan diskusi lanjutan, pemberian tugas dan pembahasan tugas terkait pemanfaatan pasar digital bagi para pelaku UMKM yang berkeinginan untuk melakukan ekspor. Diskusi diawali dengan membahas seberapa penting ketersediaan Email, Web dan katalog bagi Ekspor produk UMKM diantaranya 1) Sarana Penjualan Produk, 2) Mempermudah Komunikasi Meningkatkan Trust tentang usaha anda, 3) Sarana Publikasi Resmi Perusahaan, 4) Branding, dan 5) Kemudahan Memberikan Informasi. Setelah menyiapkan email, web dan katalog maka hal terpenting yang perlu dipelajari adalah memanfaatkan website Ecommerce pengembangan pasar ekspor baik yang berasal dari Indonesia maupun Negara lain. E-commerce yang ada dapat berupa website E-commerce Business to Business
(B2B) maupun website e-commerce business to consumer (B2C). Website e-commerce B2B diperuntukan bagi transaksi elektronik antara perusahaan satu dengan perusahaan lainnya. Website jenis ini biasanya akan digunakan skala produsen dan grosir atau grosir dan pengecer. Contoh: made-in-china.com atau ec21.com (Sirclo.com, 2018). Sedangkan website e-commerce business to consumer (B2C) adalah Website tipe ini melakukan kegiatan transaksi online antara produsen atau perusahaan dengan konsumen akhir. Bisnis ini berhubungan langsung dengan konsumen perorangan atau grup dan bukan dengan perusahaan atau bisnis lainnya seperti website E-commerce B2B. Contoh: alibaba.com atau ebay.com.

\section{Pentingnya Memiliki akun E-Commerce \\ Pemanfaatan e-commerce dalam} transaksi bisnis banyak mengalami peningkatan terutama selama pandemik. Beberapa keuntungan transaksi melalui $E$ Commerce dari sisi konsumen diantaranya 1). belanja secara online lebih praktis daripada belanja secara konvensional pada toko retail, 2) Konsumen dapat segera memperoleh informasi tentang produk yang dibutuhkannya, 3) Konsumen dapat melakukan transaksi pembelian dimana saja dan kapan saja, baik dari rumah, kantor, warnet, atau tempat lainnya secara online.

Dari sisi pelaku usaha, e-commerce mempermudah cara UMKM melakukan bisnis. E-commerce juga membuat operasional perusahaan menjadi lebih efisien. Pelaku usaha tidak perlu kantor dan toko fisik. Pelaku usaha bisa memasarkan produknya dari rumah atau dari mana saja. E-commerce juga sangat efisien dari sudut waktu. Pencarian informasi produk dan transaksi dapat dilakukan lebih cepat dan akurat (Karyati, 2019).

Oleh karena itu, saat ini E-commerce menjadi salah satu sarana UMKM menembus pasar ekspor. Banyak kelebihan yang ditawarkan e-commerce untuk mengembangkan UMKM, walaupun ada beberapa kendala yang akan dihadapi. Beberapa kendala bagi pengusaha yaitu penguasaan teknologi yang masih rendah, dan adanya keinginan untuk mengoptimalkan penggunaan e-commerce. Banyak yang kurang paham teknologi dan malas mempelajari teknologi baru. Sedangkan, para palaku UMKM harus pro aktif dalam mempelajari teknologi baru demi kemajuan bisnisnya sendiri. Selain itu kurang meratanya infrastruktur teknologi informasi di berbagai daerah, jaringan internet yang masih terbatas khususnya di daerah terpencil Indonesia, membuat pelaku UMKM 
daerah susah masuk ke dalam e-commerce (Karyati, 2019).

Salah satu akun B2B yang dapat dibuat adalah EC21. Berikut langkah-langkah untuk membuat akun EC21 :

1. Masuk ke https://www.ec21.com/

2. Join Free (Di pojok kiri atas tampilan web)

3. Mengisi form pendaftaran

4. Create my account

Setelah langkah tersebut dilakukan, maka pelaku usaha sudah memiliki akun. Selanjutnya adalah mengoptimalkan penggunaan akun tersebut untuk memasarkan komoditas ekspornya. Langkah yang dapat dilakukan berikutnya, diantaranya :

- $\quad$ Log in

- Mengisi Profil usaha di "My Accounts"

- Submit

- Posting Produk di "My Products"

Pelaksanaan dan penilaian tugas membuat akun E-Commerce peserta UMKM dalam workshop tersebut berjalan dengan sangat baik. Semua peserta dapat membuat akun di salah satu website. Setelah mengikuti workshop, semua peserta diharapkan sudah memiliki sarana dalam melakukan pemasaran digital untuk komoditas ekspor.

\section{Pentingnya Pembuatan Deskpripsi Produk}

Pengetahuan tentang pemanfaatan media digital harus juga dibarengi dengan pemahaman pembuatan deskripsi produk ekspor yang baik dan menarik. Deskripsi produk merupakan sarana pemasaran melalui E-Commerce. Deskripsi Produk juga merupakan cara untuk melakukan product knowledge atau perkenalan produk kepada calon pembeli.

Deskripsi produk sebaiknya tidak ditulis seadanya. Semakin paham calon buyer ketika membaca deskripsi produk, maka akan besar peluang produk akan terjual. Tugas kedua yang diberikan dalam workshop adalah membuat deskripsi produk ekspor. Beberapa langkah awal yang dapat dilakukan UMKM yang baru akan mencoba ekspor diantaranya :

1. Masuk ke Export Marketplace tertentu

2. Mempelajari istilah/deskripsi yang digunakan komoditas yang akan diekspor oleh eksportir lainnya.

3. Sesuaikan dengan apa yang akan ditawarkan

Setelah langkah awal tersebut, UMKM harus juga memperhatikan informasi yang harus ada dalam deskripsi produk ekspor, diantaranya harus ada :
1. Nama/Brand Produk

2. Spesifikasi Produk

3. Minimal Order Quantity

4. Harga (FOB/CNF/CIF)

5. Cara Pembayaran

6. Delivery Time

Beberapa tips lain yang perlu dilakukan supaya deskripsi produk dapat berdampak secara optimal, diantaranya 1) Tentukan target pemasaran, 2) Gunakan kalimat persuasif, 3) Tampilkan foto dan video yang menarik, dan 4) Hindari kata-kata yang berlebihan (Kontenesia.com, 2021) Selain itu untuk mengoptimalkan pasar digital dan menjaga kepercayaan calon pembeli dapat dilakukan juga beberapa cara lain diantaranya :

1. Jangan tunda untuk menjawab / reply email permintaan buyer segera,maksimal $1 \times 24$ jam harus sudah terjawab

2. Apabila sedang dalam perjalanan atau kesulitan untuk menjawab, segera reply email dengan alasan yang bisa diterima.

3. Jika ada yang kurang jelas atas permintaan customer, jangan ragu untuk meminta penjelasan dari mereka

4. Selama berkomunikasi jangan ada kesan mencurigai calon buyer.

Pelaksanaan tugas kedua terkait pembuatan deskripsi produk oleh peserta workshop memiliki kendala umum yaitu keterbatasan kemampuan mendeksripsikan produk menggunakan bahasa asing. Namun setelah dilakukannya pendampingan, beberapa pelaku UMKM telah dapat menampilkan deskripsi produknya melalui akun e-commerce yang sebelumnya telah dibuat.

\section{Dokumentasi Kegiatan}

Berikut beberapa foto kegiatan pengabdian masyarakat workshop ekspor impor yang dilaksanakan pada 29 Agustus 2021. 


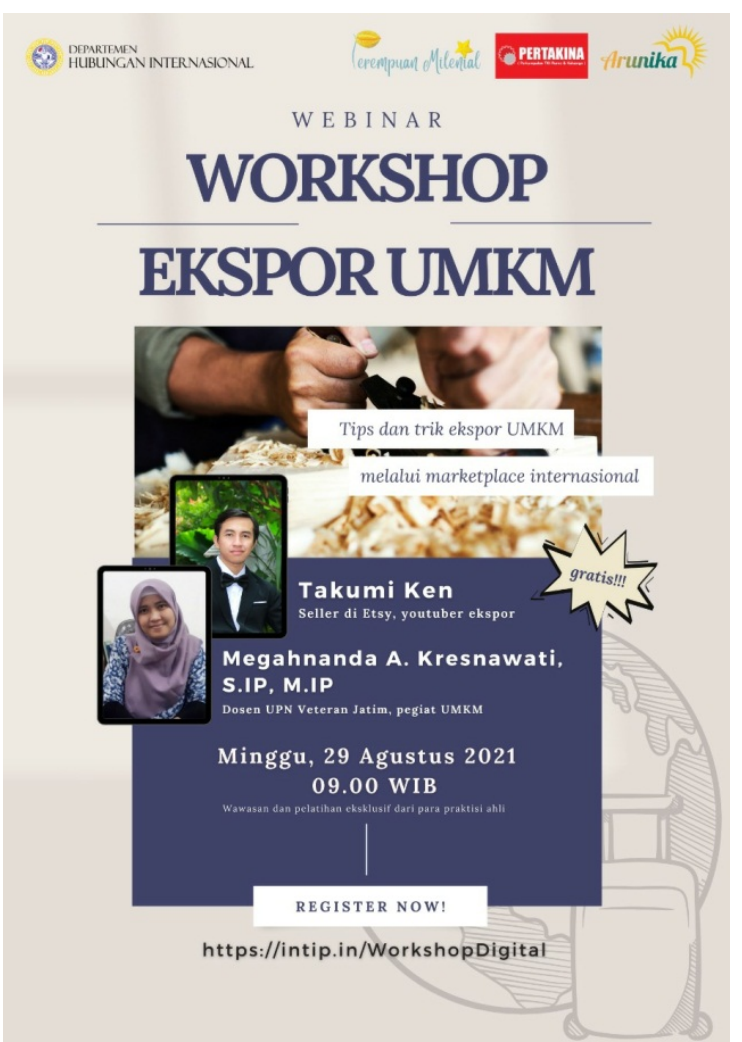

Gambar 3. Poster Acara Workshop Ekspor UMKM

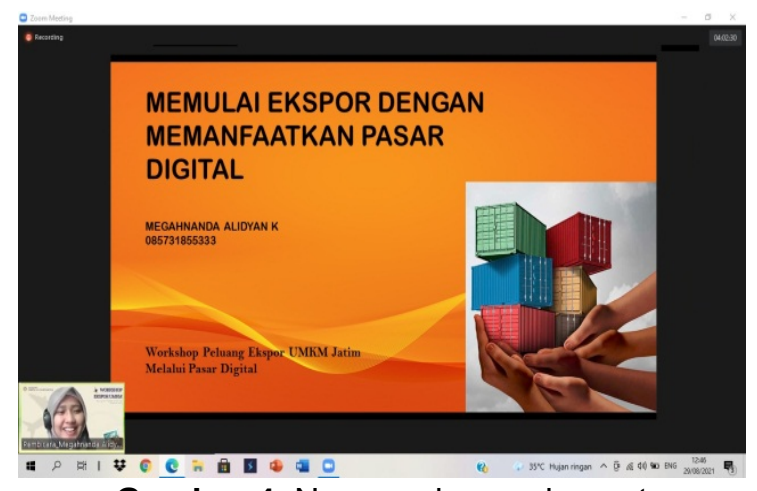

Gambar 4. Narasumber pada saat memberikan materi kepada peserta

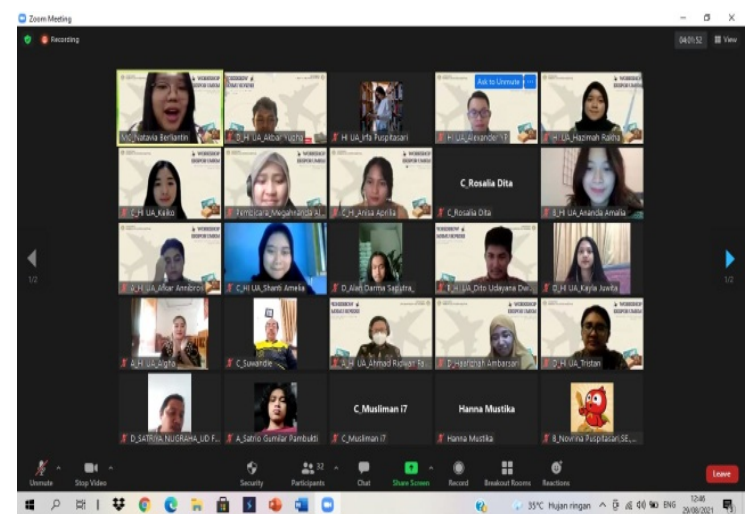

Gambar 5. Para Peserta Workshop dan Narasumber

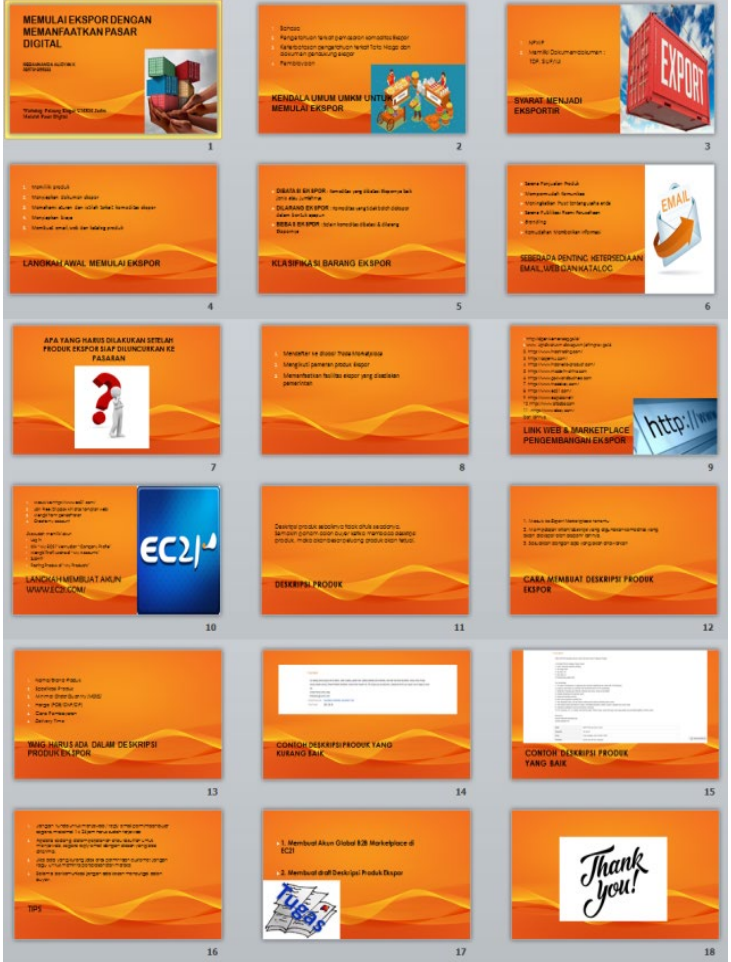

Gambar 6. Slide Materi yang diberikan kepada para peserta

\section{SIMPULAN}

Saat ini banyak pelaku UMKM telah menyadari dampak positif perkembangan era digital yang dapat mempercepat dan mempermudah transaksi penjualan dan pembelian. Utamanya di masa pandemik ini pemanfaatan media digital dalam pengembangan pasar ekspor UMKM merupakan salah satu cara UMKM untuk mempertahankan dan mengembangkan pasarnya. Walaupun ada beberapa kendala saat sesi praktek seperti banyaknya penggunaan bahasa asing dalam praktek pembuatan akun website E-Commerce maupun pembuatan deskripsi produk. Peserta workshop masih dapat mengikutinya dengan baik karena adanya pendampingan. Oleh karena itu, Workshop yang telah dilakukan diharapkan dapat membawa manfaat besar untuk pengembangan ekspor UMKM melalui pasar digital khususnya di Jawa Timur.

\section{UCAPAN TERIMAKASIH}

Terima kasih kepada UPN "Veteran" Jawa Timur dalam mendukung setiap kegiatan pengabdian masyarakat yang dilakukan. Begitu juga dengan Universitas Airlangga selaku penyelenggara Workshop yang telah melibatkan berbagai pihak untuk kesuksesan penyelenggaraan workshop. 


\section{DAFTAR RUJUKAN}

Karyati, I. P. (2019, September 13). ECommerce untuk UMKM Dan Pertumbuhan Ekonomi Indonesia. Retrieved Agustus 5, 2021, from https://bppk.kemenkeu.go.id/: https://bppk.kemenkeu.go.id/content/b erita/pusdiklat-keuangan-umumecommerce-untuk-umkm-danpertumbuhan-ekonomi-indonesia2019-11-05-ebe6e220/

Katadata.co.id. (2020, Juni). Digitalisasi UMKM di Tengah Pandemi Covid-19. Retrieved September 30, 2021, from https://katadata.co.id/: https://katadata.co.id/umkm

Kompas.com. (2020, Agustus 18). Go Digital, Pemerintah Jatim Ajak UMKM Manfaatkan Program \#TerusUsaha Milik Grab. Retrieved September 30, 2021, from https://amp.kompas.com: https://amp.kompas.com/money/read/2 020/08/18/143600626/go-digitalpemerintah-jatim-ajak-umkmmanfaatkan-program-terususaha-milikgrab

Kontenesia.com. (2021, Juni 02). Membuat Deskripsi Produk yang Tepat untuk Menarik Minat Pembeli. Retrieved Agustus 5, 2021, from https://kontenesia.com/:

https://kontenesia.com/deskripsiproduk/

Pamungkas, I. C. (2021, July 1). Dampak COVID-19 terhadap Perdagangan Internasional di Indonesia. Retrieved September 28, 2021, from https://kumparan.com/:

https://kumparan.com/ivan-cahyapamungkas/dampak-covid-19terhadap-perdagangan-internasionaldi-indonesia-1w4amVHCdl2

Sirclo.com. (2018, Mei 2016). Mengenal JenisJenis Website E-commerce Berdasarkan Model Bisnisnya. Retrieved Agustus 5, 2021, from https://www.sirclo.com/:

https://www.sirclo.com/mengenaljenis-jenis-website-e-commerceberdasarkan-model-bisnisnya/

Totoaminoto. (2019, Mei 16). Klasifikasi Barang Ekspor. Retrieved Agustus 5, 2021, from https://www.Ispeii.co.id/: https://www.lspeii.co.id/2019/05/16/kla sifikasi-barang-ekspor/

Widarti, P. (2021, Agustus 9). UMKM Jatim Didorong Masuk Ekosistem Digital. Retrieved September 30, 2021, from https://m.bisnis.com/:

https://m.bisnis.com/amp/read/202108 09/531/1427683/umkm-jatim-didorongmasuk-ekosistem-digital

Zahro, F. (2021, Maret 21). UPT Pelatihan Diresmikan di Malang, Akan Dimaksimalkan Bantu Digitalisasi IT Koperasi dan UKM Jatim. Retrieved September 30, 2021, from https://surabaya.tribunnews.com/: https://surabaya.tribunnews.com/amp/ 2021/03/30/upt-pelatihan-diresmikandi-malang-akan-dimaksimalkan-bantudigitalisasi-it-koperasi-dan-ukm-jatim 